\title{
Analysis of the Dependence of the Cryptocurrency Rate on Updates in the Technical Part of the Mining Process
}

\author{
Jasur Ataniyazov a , Shokhsanam Shirinova ${ }^{\text {b }}$ \\ ${ }^{a}$ Professor, Head of the Dept. of International finance and credit, Tashkent Institute of Finance, \\ Uzbekistan, \\ Email: jasurbek156@gmail.com, ORCID: 0000-0002-4758-0781 \\ ${ }^{\mathrm{b}}$ Shirinova Shohsanam, teacher, Dept. of International finance and credit, Tashkent Institute of \\ Finance, Uzbekistan, Email: shokhsanam2828@gmail.com, ORCID: 0000-0001-7276-8965
}

Article History: Received: 10 November 2020; Revised 12 January 2021 Accepted: 27 January 2021; Published online: 5 April 2021

\begin{abstract}
Monetary policy bodies in almost all countries of the world, regardless of the level of development of the economy and financial market, were not ready for the emergence and rapid development of digital currencies and, in particular, for their virtual variety - cryptocurrency.The development of technology constantly brings something new into our life, sometimes completely incomprehensible and unpredictable. An example of such a phenomenon is cryptocurrency. Many studies aimed at finding the exact factors on which the rate of cryptocurrencies may depend have not shown significant results. This study is aimed at finding the dependence of the cryptocurrency exchange rate on updates in the technical aspect of the cryptocurrency mining process.
\end{abstract}

Keywords: cryptocurrency, mining, technology,bitcoin, etherium.

\section{Introduction}

Scientific and technological progress inevitably leads to the emergence of new types of social activity. Their acceptance by society, understanding of their content and goals is not always a simple and fleeting process. The fourth industrial revolution, which unfolded before our eyes, intensified these processes. The digitalization of the economy and the changes associated with it require, in our opinion, much more effort from lawyers than before. Why? The answer is obvious. Almost all of us, humanities, are, at best, "advanced users" of various technical devices. The basic training programs for lawyers, including highly qualified personnel, did not include, and often does not include, "digital literacy". Few of these programs are offered in the additional education system. Therefore, the transition from "education for life" to "education throughout life" is becoming more than urgent. It is customary to call a crypto currency a kind of digital currency that does not have a material or electronic form and is a number that denotes the amount of data units of account recorded in the corresponding position of the information package of the data transfer protocol.

The main advantage of crypto currencies is that they are decentralized, that is, they do not have an internal or external administrator or any equivalent. The release of crypt currency is carried out by anyone; its emission is carried out by solving certain mathematical problems on electronic devices. First, we need to understand where the crypto currency came from and how it even achieved recognition in some developed countries.

On October 31, 2008, a certain person or group of people (the data is still not confirmed) Satashi Nakamoto published an article "Bitcoin: A Peer-to-Peer Electronic Cash System", in which he explained such a concept as "Blockchain". We need this concept to understand why and where people receive rewards in the form of crypt currency, in our case we will analyze Bitcoin.

Blockchain is the process of composing blocks according to a specific system. In this system, a certain number of transactions carried out between the owners of the crypto currency is recorded in one block. The blocks are connected in a chain, each link of which is connected to all previous ones using a certain code. Let's imagine that there are millions of network members. Each participant keeps a list (or a compiled chain) with the transactions of all others, there is no single database - complete decentralization. Each participant in the network needs to record their transactions, while they must be verified by all other participants and registered in their lists. The question arises: how to protect this system from attributing additional transactions by its participants? Its protection is due to the fact that when a person tries, for example, to pay off his account, he must independently prove that he has the necessary funds. He proves this not with a balance, as is the case with banks 
and bank cards, but with information about transactions that are already contained in blocks and that are already registered with all network participants. These tasks are needed to confirm transactions that occur between cryptocurrency users.

\section{Significance Of The Study}

One of the most obvious ways to make money in a new market is to start mining: transferring your own computing power to maintain a distributed platform and creating new blocks on the blockchain with the ability to receive rewards in the form of new cryptocurrency units and commission fees. Simply put, the user gives off the power of his computer to the "air", receiving in return a certain amount of cryptocurrency. Millions of people around the world have been following this path for several years, including in Uzbekistan. At the dawn of mining, it was not difficult to generate digital coins: the user installed special software on his computer, which transferred its power to the blockchain. But the more virtual currency is mined, the higher its "price" becomes: the power required to produce each new coin increases exponentially. Mining of the most popular cryptocurrency Bitcoin and the recently launched Bitcoin Cash today accounts for up to $0.13 \%$ of global electricity consumption. And this figure is constantly growing, as the complexity of the Bitcoin network is increasing by an average of $10 \%$ per month (and on some other digital currencies, this growth can reach 50-60 times a month). Today, GPU mining is suitable for a huge number of altcoins, but Bitcoin cannot be mined on video cards. The Bitcoin network is too complex, requiring special industrial equipment to work.

\section{Review Of Related Studies.}

US Federal Reserve experts A. Berentsen and F. Shar [2] characterize various currencies in accordance with their governance structure, focusing on cryptocurrencies and government-issued money; they acknowledge that there is a large pent-up demand for a liquid asset that allows households and firms to save outside the private financial sector. A. Carstens, head of the Bank for International Settlements, in his report draws the attention of central banks and regulators to the relationship of cryptocurrencies with real currencies, as well as the need to comply with the unity of regulatory requirements, without allowing any exceptions [3]. A. Kumar and S. Christie [1], examining the functionality of bitcoins, state that central banks currently do not consider cryptocurrencies as a significant threat due to their insignificant share in the total circulation of financial instruments. Analysts from the Central Bank of Finland [4] concluded that bitcoin may be more comparable to money than to a modern electronic payment system, and there is no need to regulate it, because as a system it adheres to a protocol, and transaction fees are determined by users regardless of efforts of "earners". Bank of Canada economists B. Fung and H. Galaburda [5] point out that digital currency will be accepted by market participants only if it is more attractive to use or better suited to meet their payment needs than existing alternatives.

\section{Results and discussion}

Now let's figure out where BitCoin comes from in this whole system. The whole complexity of the constructed system lies in the fact that in order to write a block with transactions, you must have a code (the one that starts with ten zeros). Several transactions are written to the block, so that all network participants are interested in finding this code as quickly as possible. Thus, the owners of computing power have an incentive to direct them to find the right combination. All participants are looking for a code that can be assigned to a block. This problem is solved only by the selection method. According to statistics, a new code is found every 10 minutes, taking into account the fact that the search for a solution uses the power of millions of computers around the world, including the real data centers of huge corporations. But there is only one lucky person who finds a suitable code, and it is he who receives the reward from the system in the form of Bitcoina. For this luck, our hero receives 12.5 coins (2017), which in our time at the exchange rate equals 240 thousand dollars. In the process of mining the currency, the reward in the form of bitcoin will decrease. Naturally, few people are involved in mining (bitcoin production) alone. As a rule, miners are united in pools and contribute to the solution of a common problem. The award is divided into equal parts between the participants.

The amount of cryptocurrency, in our case bitcoin, has its limit, because the number of codes starting with 10 zeros is limited, and soon all this currency will be mined. But despite all the seemingly complexity of this process, each of us can create something like this sitting at home with a laptop, hence a huge number of startups associated with cryptocurrency arise.

Now let's look at the technical part of the cryptocurrency mining process. The mining farm is a regular computer with some modifications.

- The basis of any computer - the motherboard, must be of fairly good quality, to connect as many video cards as possible. 
- The quality and power of the processor is not an important factor, therefore, the cheapest one is selected, with the ability to connect to the motherboard.

- Random access memory, hard disk are not important during work. They are necessary just for the system to work.

- The power supply is an extremely important part of the system. Video cards as the main data centers require enormous power to operate, so it must be powerful and stable.

- The most important part of the farm is the video card. The main and most expensive component of a mining farm, the capacity of which will allow us to search for the coveted code.

- And the last part - the cooling system tuned for all this.

In this list, we are interested in the most expensive part of the farm - the video card. Initially, video cards were in demand in such industries as: game design, 3D design, engineering, and others. With the advent, distribution and development of cryptocurrency mining technologies, the demand for video cards has increased dramatically. There are two main competitors in this market - AMD and NVIDIA. At the moment on the market, you can pick up a definite graphical solution for your task. In addition, advances in technology will allow companies to constantly update their products. A huge number of solutions are also suitable for mining. But the inability to buy new, just announced, video cards has become a frequent occurrence. This phenomenon is associated with high demand among miners. Despite the price of top models, which reach 137,000 rubles in Russia, they simply cannot be found. Despite the price, the payback period for new solutions from NVIDIA announced in September 2020 is no more than 200 days, and solutions from AMD announced in October of the same year are 150 days. The payback period and profitability of this investment, especially for people with already operating farms, is self-explanatory. Let's try to find a reflection of the emergence of new technical solutions on the cryptocurrency course.

Theoretical works on cryptocurrency clearly show that the bitcoin rate depends only on the demand for the currency, its supply and network effect. It is necessary to clarify what the network effect is. This is the effect of the amount of consumed resource on its cost. Using the example of cryptocurrency, this effect can be explained as follows: the more people use a particular cryptocurrency, the greater its value, because it can be used to pay off a large number of people.

Now let's take a look at what a mining farm consists of? The main function in the mining of cryptocurrency is performed by video cards, but to assemble a mining farm, you also need:

- Motherboard. It is the foundation of the entire system. The number of video cards that can be installed depends on the motherboard. The cheapest motherboard ASRock FM2A88M costs about 4,800 rubles. But for the efficiency of the farm, you should choose a more powerful option. For example, the ASRock FM2A88X board costs 8350 rubles. You can put up to 6 video cards on it. This option is optimal.

- Housing. To save money, you should assemble the frame yourself. For this, it is best to use aluminum corners or wooden bars. With self-assembly, the cost will be about 1000 rubles.

- $\quad$ RAM. You need at least 4 GB to run the OS. Alternatively, you can buy two boards of 2 gigabytes each, it will be more economical. The cost of one board will cost 1,300 rubles;

- Average power processor. It must definitely fit the motherboard. An economical option is a processor of category A-4, it costs 3650 rubles.

- $\quad$ Power Supply. Its main characteristic is power. The block must match the parameters of the system. It is important to choose a unit that provides a power reserve within $20 \%$.

- 60 gigabyte hard drive. The minimum price is 3,000 rubles.

- Adapters and switch button;

- Cooling elements (cooler, thermal paste).

- Video card (s) with at least 2 GB memory.

To purchase components for assembling a farm, you need to know the hash rate of video cards. Hashrate is a unit of measurement that allows you to determine the computing power of devices when mining cryptocurrency. Based on this speed, you can determine what the income will be in a particular network for a certain complexity. It is recommended to study the hash tables of video cards. As for the performance of processors, the following parameters are leading: 
1. The amount of memory. The more memory, the better, but in the long run the best video cards for mining with the maximum storage capacity. For example, recently Ether (cryptocurrency) could be mined on 2GB cards, today you need at least 4 GB of video memory.

2. Width of the bus. Graphics cards for mining with a 256-bit bus are much more efficient than 128-bit ones.

3. Cooling system. Graphics cards with multiple fans and heat pipes are less prone to wear and tear when used 24/7. You can buy a graphics card with a turbine, but it is very noisy.

4. Power consumption. AMD R9 GPUs are still on sale today, they are almost as powerful as the best mining graphics cards for the newer Rx 500 series, but they consume a lot more power.

It is best to opt for AMD products, because mining cryptocurrency on an NVidia GeForce video card is not so efficient, and such a farm will pay off much slower. Mining cryptocurrency on an AMD Radeon video card is 16-18\% more efficient than mining on similar cards from NVidia, for this reason, we will consider only products under the Radeon brand.

\section{Most Eligible Models: Radeon RX Vega, Radeon RX 580, and Radeon RX}

570. Let's conditionally divide them into the highest, middle and lowest price category.

\section{1) AMD Radeon RX Vega graphics card}

One of the most productive cards to date. However, the price of this card is not less than 57,000 rubles.

In order for a mining farm to be considered competitive, it must have from 3 to 6 video cards. Accordingly, the purchase of 6 video cards will cost 342,000 rubles. Despite its high price, the Vega offers outstanding performance.

2) AMD Radeon RX 580 video card A very decent hardware solution. The amount of memory and performance is inferior to the previous one, but it costs 2 times cheaper.

A good copy of such a video card can be bought for 27 thousand rubles, and for 6 video cards you will have to pay 162 thousand rubles.

\section{3) AMD Radeon RX 570 graphics card}

An excellent choice for home mining, but the smallest possible graphics card in order to build a farm for successful mining. When choosing these components, it should be understood that it will not be possible to mine the first echelon crypt (with the exception of Ethereum) and you will have to think very carefully not only about the mining strategy, but also to study the forecasts for the growth of the cryptocurrency.

Components are sold at a price of about 23,000 rubles. That is, 6 cards will cost 138,000. It is also worth noting that cryptocurrency mining on an NVidia GeForce video card is ineffective, and the RX 570 is almost a complete analogue of this adapter.

\section{5. .Data Analysis and Interpretation}

When installing video cards to ensure their cooling during mining, risers are used that connect video cards to the PCI-Express connector on the motherboard through an extension cable - a high quality USB cable and provide a separate power circuit for the video card, decoupled from the motherboard. Their selection is very important to ensure the reliable operation of the rig.

It is best to use a 12-volt riser with a 6-pin power connector, because they usually have a built-in fuse, and also have more reliable built-in circuits for converting the 12 volt supply to others required for video cards. In addition, 6-pin risers have three wires for each power pole, which provides a more even load on the connectors.

Table 1. Total farm cost

\begin{tabular}{|c|c|c|}
\hline Name & Quantity & $\begin{array}{c}\text { Cost (in } \\
\text { rubles) }\end{array}$ \\
\hline $\begin{array}{c}\text { GIGABYTEH110-D3A Bitcoin Edition } \\
\text { motherboard }\end{array}$ & 1 & 7200 \\
\hline $\begin{array}{c}\text { Intel Pentium G4600 Kaby Lake } \\
\text { Processor with Cooler }\end{array}$ & 1 & 4700 \\
\hline AMD Radeon SSD & 1 & 2500 \\
\hline RAM Samsung DDR4 2133 DIMM 4Gb & 1 & 3000 \\
\hline
\end{tabular}




\begin{tabular}{|c|c|c|}
\hline AMD Radeon RX Vega Graphics & 6 & 342000 \\
\hline $\begin{array}{l}\text { CoolerMaster MasterWatt Maker 1200W } \\
\text { Power Supply }\end{array}$ & 1 & 19800 \\
\hline Raiser & 6 & 2400 \\
\hline
\end{tabular}

In total, a home farm will cost 381600 RUB, provided that you have a monitor, mouse and keyboards, as well as all the necessary adapters to connect the monitor

Most of the miners who decide to start mining Bitcoins or other cryptocurrencies do not want to be left with their nose. This is normal. Calculate the profitability of a cryptocurrency farm yourself, taking into account a number of key factors:

- Speed of solving problems MH / S;

- Equipment price;

- The current rate of Bitcoin or other cryptocurrency that you are going to mine;

- Farm capacity and tariff for $1 \mathrm{KW} /$ hour.

Given these criteria, you will find out in how many months the investment in the equipment will pay off. Practice shows that the increased complexity of solving problems (hashes) and the high cost of hardware make the creation of a mining farm an unprofitable enterprise.

If video cards are used improperly, overclocking them to $120 \%$, the hardware will burn out after 1-3 months, partially recouping the initial investment.

Numerous studies cannot find fairly accurate factors to describe changes in the cryptocurrency exchange rate. It can be assumed that with the advent of new video cards, the amount of produced currency begins to grow, which will cause oversaturation of the market and, as a result, a drop in prices. That is, certain phenomena of announcements and releases of new solutions should be reflected in the exchange rate. We will look for confirmation of this theory based on announcements and outputs of video cards most suitable for mining. We will look for reflections on BitCoin and Ethereum rates.

On certain resources, you can find the most suitable video cards for mining, taking into account their capacities and the level of energy consumption. [2] Let's select them and define the events associated with their appearance in the markets.

Table 2. The evolution of the emergence of video cards in the mining market.

\begin{tabular}{|c|c|c|}
\hline $\begin{array}{l}\text { Numbe } \\
\text { r of event }\end{array}$ & Date & Event \\
\hline 1 & January 10, 2019 & AMD Radeon VII Announcement \\
\hline 2 & February 7, 2019 & AMD Radeon VII graphics output \\
\hline 3 & June 11, 2019 & $\begin{array}{l}\text { AMD Radeon RX } 5700 \text { XT and } \\
\begin{array}{l}\text { Radeon RX } 5700 \\
\text { announced }\end{array} \\
\text { andeo cards }\end{array}$ \\
\hline 4 & July 7, 2019 & $\begin{array}{l}\text { AMD Radeon RX } 5700 \text { XT and } \\
\text { Radeon RX } 5700 \text { release }\end{array}$ \\
\hline 5 & September 4, 2020 & $\begin{array}{l}\text { Announcement of a new generation } \\
\text { of NVIDIA video cards (NVIDIA } \\
\text { GeForce RTX 3090, NVIDIA GeForce } \\
\text { RTX 3080, NVIDIA }\end{array}$ \\
\hline 6 & September 17, 2020 & $\begin{array}{llll}\text { NVIDIA } & \text { GeForce } & \text { RTX } & 3080 \\
\text { released, }\end{array}$ \\
\hline 7 & September 24,2020 & NVIDIA GeForce RTX 3070 \\
\hline 8 & October 28,2020 & $\begin{array}{cccc}\begin{array}{l}\text { NVIDIA } \\
\text { released }\end{array} & \text { GeForce } & \text { RTX } & 3090 \\
\end{array}$ \\
\hline
\end{tabular}




\begin{tabular}{|c|c|c|}
\hline 9 & November 18, 2020 & $\begin{array}{c}\text { AMD Neneration } \\
\text { Announcement (Radeon RX 6800 XT } \\
\text { and RX 6800, Radeon RX 6900 XT) }\end{array}$ \\
\hline 10 & December 8, 2020 & $\begin{array}{c}\text { Radeon RX 6800 XT and Radeon } \\
\text { RX 6800 output }\end{array}$ \\
\hline
\end{tabular}

Further, using the data presented above and using the available statistical Internet resources, we will look for sharp deviations in the rate of cryptocurrencies. [3] Let's admit adding an error of 2-3 days. Let's divide the phenomena into announcements and the equipment outputs themselves into two tables. Highlighted in yellow events related to AMD.

Table 3. The announcement of the leaps in the cryptocurrency rate.

\begin{tabular}{|c|c|c|c|c|}
\hline № & Leaps Dates & $\begin{array}{c}\text { Bitcoin exchange rate } \\
\text { changes }\end{array}$ & Leaps Dates & $\begin{array}{c}\text { Ethereum course } \\
\text { changes }\end{array}$ \\
\hline 1 & January 9-12, 2019 & $-9,6 \%$ & $10-13$ января 2019 & -24 \\
\hline 3 & 11-13 June 2019 & +4 & $11-13$ июня 2019 & +8.3 \\
\hline 5 & 4-6 September 2020 & $-3,5$ & $4-6$ сентября 2020 & $-15,8 \%$ \\
& & $-10,5$ & & $-3.7 \%$ \\
\hline 8 & 3-4 September 2020 & $-3.7 \%$ & $28-29$ октября & \\
\hline
\end{tabular}

Table 4. Equipment release

\begin{tabular}{|c|c|c|c|c|}
\hline № & Leaps Dates & $\begin{array}{c}\text { Bitcoin exchange rate } \\
\text { changes }\end{array}$ & Leaps Dates & $\begin{array}{c}\text { Ethereum course } \\
\text { changes }\end{array}$ \\
\hline 2 & $7-9$ February 2019 & +7.2 & $7-8$ February 2019 & +13.5 \\
\hline 4 & July 7-9, 2019 & +9.5 & July 7-9, 2019 & $+9.4 \%$ \\
\hline 6 & September 17-20 & $\begin{array}{c}\text { No strong deviations } \\
\text { were observed }\end{array}$ & September 17-18 & $\begin{array}{c}\text { No strong deviations } \\
\text { were observed }\end{array}$ \\
\hline 7 & September 24-25 & +4.5 & September 24-25 & $+7.1 \%$ \\
\hline 9 & November 18-19 & -4.6 & November 18-19 & $-3.7 \%$ \\
\hline
\end{tabular}

\section{Conclusion}

Analysis of these tables allows us to draw several conclusions:

1) some announcements cause a very strong drop in the rate of cryptocurrencies, but it is difficult to keep track of any pattern.

2) almost any release of new video cards leads to an increase in the cost of currencies. The exception was the release of AMD video cards on November 18, 2020. This can be explained by the fact that on November 18 the youngest and middle of the new generation of the video card came out. Perhaps a reflection of the growth will appear on December 8th.

One of the possible explanations for the sharp rise in the value of the currency at the time of the release of new advanced equipment can be explained using the network effect. At the moment of release, people who were able to purchase a new powerful video card enter the cryptocurrency market and begin to mine in full in order to return the funds used in the purchase. It is also worth taking into account that since September 2020, the rate of cryptocurrencies has begun to actively grow. So the last serious failure of bitcoin was in early September, at the time of the announcement of new NVIDIA video cards. After that, in three months the rate almost doubled. The situation is similar with Ethereum.

\section{References.}

[1]. Blockchain: description of technology in simple words. URL: https://finkontrol.com/crypto/chto-takoeblokcheyn/ (13.12.2018)

[2]. Hashgraph is the killer of the blockchain. URL: https://smart-lab.ru/blog/431134.php (13.12.2018) 
[3]. S. Raval. Decentralized applications. Blockchain technology in action / S. Raval, 2017 .-- 192 p.

[4]. N. Prati. Blockchain. Application development / N. Prati, 2018 .-- 256 p.

[5]. Cryptocurrency and blockchain technology in the digital economy: the genesis of development / Babkin A.V., Burkaltseva D.D., Pshenichnikov V.V., Tyulin A.S. // Scientific and technical statements of SPbSPU. Economic sciences. 2017.Vol. 10, No. 5. P. 9-22. DOI: 10.18721 / JE.10501 